\title{
Penentuan Kadar Minyak Atsiri Kulit Jeruk Sunkist (Citrus sinensis L. Osbeck) sebagai Alternatif Peluruh Sterofoam Alami
}

\author{
Annisa E. Fitrianti, Yockie Dheafithraza, Nadhira Handayani, Nadiya N. Afifah, Siti \\ Mariyam \\ Fakultas Farmasi Universitas Padjadjaran, Sumedang, Jawa Barat, Indonesia
}

\begin{abstract}
Abstrak
Sterofoam banyak digunakan di segala bidang namun sifatnya yang sulit untuk diurai menjadikannya sebagai salah satu limbah abadi. Beberapa penelitian membuktikan bahwa kandungan limonene dari kulit jeruk sunkist (Citrus sinensis L. Osbeck) terbukti mampu meluruhkan sterofoam dengan hasil yang cukup banyak, namun belum ditetapkan kadar yang efektif. Penelitian ini bertujuan untuk mengetahui kadar minyak atsiri kulit jeruk sunkist terkecil yang masih efektif untuk meluruhkan sterofoam. Minyak atsiri diisolasi dengan metode distilasi dan dekantasi, kemudian dilakukan penentuan kadar. Hasil pengamatan menunjukkan setiap 300 gram kulit jeruk sunkist menghasilkan destilat rata-rata sebanyak $5 \mathrm{~mL}(1,67 \%(\mathrm{v} / \mathrm{b}))$. Kadar minyak atsiri kulit jeruk sunkist yang efektif untuk meluruhkan sterofoam adalah $25 \%$ dengan perbandingan minyak atsiri kulit jeruk sunkist : etanol : air adalah $1: 1: 2$. Massa sterofoam maksimum yang dapat diluruhkan oleh $1 \mathrm{~mL}$ minyak atsiri tersebut berbeda-beda tergantung pada jenis sterofoam yang digunakan. Sterofoam yang paling banyak diluruhkan oleh kulit jeruk sunkist $25 \%$ adalah sterofoam papan pengumuman yaitu sebanyak $200 \mathrm{mg} / \mathrm{mL}$. Minyak atsiri kulit jeruk sunkist dapat digunakan sebagai peluruh sterofoam alami.
\end{abstract}

Kata Kunci: Limbah, kulit jeruk sunkist, peluruh, sterofoam

\section{Determination of Essensial Oil Concentration of Sunkist Orange Peel (Citrus sinensis L. Osbeck) as A Natural Styrofoam Decomposer}

\begin{abstract}
Despite styrofoam is widely used in all fields, the difficulty to decompose makes it enduring waste. Several studies exhibited that the limonene from Sunkist orange peel (Citrus sinensis L. Osbeck) was able to demolish styrofoam quite tolerable, but the effective level had not been determined. This study aims to examine the effective levels of Sunkist orange peel essential oil to destruct styrofoam. Essential oils were isolated by the method of distillation and decantation and the level determination was done afterwards.. The results showed that every 300 grams of Sunkist orange peel distillate yield an average of $5 \mathrm{~mL}(1.67 \%(\mathrm{v} / \mathrm{w}))$. The effective levels of Sunkist orange peel essential oils to destroy styrofoam was $25 \%$ with a ratio of Sunkist orange peel essential oil: ethanol: water was 1: 1: 2 . The maximum mass of styrofoam that could be demolished by $1 \mathrm{~mL}$ of the essential oil varies depending on the type of styrofoam used. The most decomposed styrofoam by Sunkist orange peel $25 \%$ was styrofoam bulletin board which was as much as $200 \mathrm{mg} / \mathrm{mL}$. Sunkist orange peel essential oils can be used as a natural decomposer for styrofoam.
\end{abstract}

Keywords: Decomposer, sunkist orange peel, styrofoam, waste 


\section{Pendahuluan}

Sterofoam (polistirena foam) dikenal sebagai "kemasan" yang sangat praktis dan murah. Polistirena foam dihasilkan dari campuran $90-95 \%$ polistirena dan $5-10 \%$ gas seperti $n$-butana atau $n$-pentana. Polistirena ini terbuat dari monomer stirena melalui proses polimerisasi. Polistirena bersifat kaku, transparan, rapuh, inert secara kimiawi, dan merupakan insulator yang baik. Polistirena foam merupakan bahan plastik yang memiliki sifat khusus dengan struktur yang tersusun dari butiran dengan kerapatan rendah, mempunyai bobot ringan, dan terdapat pori-pori yang berisi udara yang tidak dapat menghantar panas. ${ }^{1}$

Sterofoam memiliki beberapa kelebihan yaitu awet, ringan, tahan air, ekonomis. Hal ini menjadikan sterofoam adalah pilihan untuk mempermudah pengemasan, namun ada hal lain yang perlu kita perhatikan yaitu bagaimana pengolahan sampah dari sterofoam tersebut. ${ }^{2}$

Penggunaan sterofoam berdampak buruk bagi lingkungan karena sterofoam sulit untuk didegradasi dan dapat bertahan di alam selama ribuan tahun. ${ }^{3}$

Polistirena merupakan plastik yang inert sehingga relatif tidak berbahaya bagi kesehatan, yang perlu diwaspadai adalah kemungkinan terjadinya migrasi dari monomer stirena ke dalam pangan yang dapat menimbulkan risiko bagi kesehatan. Bahaya monomer stirena terhadap kesehatan setelah terpapar dalam jangka panjang, antara lain menyebabkan gangguan pada sistem syaraf pusat, meningkatkan risiko leukemia dan limfoma, monomer stirena dapat masuk ke dalam janin. ${ }^{1}$

Peluruhan sterofoam dengan pelarut alami limonene diperkenalkan pertama kali oleh Tsutomu Noguchi 1998 untuk mendaur ulang sterofoam. ${ }^{4}$

D-limonene adalah salah satu terpen yang paling umum di alam. D-limonene adalah konstituen utama dalam beberapa minyak jeruk (jeruk, lemon, jeruk mandarin, jeruk nipis). D-limonene memiliki toksisitas yang cukup rendah. Penelitian membuktikan bahwa D-limonene tidak menimbulkan mutagenik, karsinogenik atau risiko nefrotoksik untuk manusia. ${ }^{5}$

Berdasarkan uraian di atas, penelitian ini difokuskan pada penggunaan kulit jeruk Sunkist (Citrus sinensis L. Osbeck) sebagai peluruh sterofoam alami dengan tujuan penentuan kadar minyak atsiri yang efektif untuk peluruhan sterofoam.

\section{Metode}

\section{Alat \& Bahan}

Alat yang digunakan dalam penelitian ini adalah alat distilasi, blender, spektrofotometer Inframerah (Shimadzu IR Prestige-21), dan alat-alat gelas yang umum digunakan di Laboratorium Kimia Sintesis Fakultas Farmasi Universitas Padjadjaran.

Bahan yang digunakan dalam penelitian ini adalah aquades (Lab. Kimia Sintesis, Unpad), etanol, kulit jeruk sunkist (Citrus sinensis L. Osbeck), sterofoam.

\section{Cara Kerja}

\section{Penyiapan Bahan}

Bahan yang digunakan dalam penelitian ini adalah kulit jeruk sunkist (Citrus sinensis L. Osbeck), yang diperoleh dari daerah sekitar Bandung dan Jatinangor. Sebelum digunakan kulit jeruk sunkist dibersihkan terlebih dahulu dari kotoran yang menempel.

\section{Distilasi Kulit Jeruk Sunkist}

Kulit jeruk sunkist ditimbang sebanyak 300 gram kemudian dipotong kecilkecil dan ditambahkan aquades dengan perbandingan kulit jeruk dan aquades adalah 1 gram per $1 \mathrm{~mL}$, lalu dihaluskan dengan menggunakan blender. Kemudian campuran tersebut didistilasi pada suhu $98^{\circ} \mathrm{C}$ untuk mendapatkan minyak atsiri.

\section{Analisis Kualitatif Limonene Minyak Atsiri Kulit Jeruk Sunkist}

Analisis kualitatif dengan menggunakan spektrofotometer inframerah (Shimadzu 
IR Prestige-21). Hasil distilasi kulit jeruk sunkist dioleskan di atas plat kalium bromida dan diukur. Spektrum hasil pengukuran kemudian dibandingkan dengan spektrum limonene yang terdapat pada literatur.

\section{Penentuan Kadar Efektif Minyak Atsiri Sebagai Peluruh Sterofoam \\ Penentuan kadar minyak atsiri} dilakukan dengan cara sebagai berikut, berbagai jenis sterofoam yaitu sterofoam yang digunakan untuk papan pengumuman atau majalah dinding, kemasan elektronik, wadah makanan, dan sterofoam tebal dan kompak pada wadah mie instan seduh, dibuat dengan luas permukaan $2 \mathrm{~cm}$ x $2 \mathrm{~cm}$ x $0,3 \mathrm{~cm}$; lalu ditetesi dan diukur waktu peluruhannya. Setelah diketahui kadar yang efektif, dilakukan penelitian lanjutan untuk mengetahui massa sterofoam maksimal yang dapat dihancurkan oleh kadar tersebut. ${ }^{6}$

\section{Hasil dan Pembahasan}

Kulit jeruk sunkist diperoleh dari limbah pedagang jus maupun dari jeruk

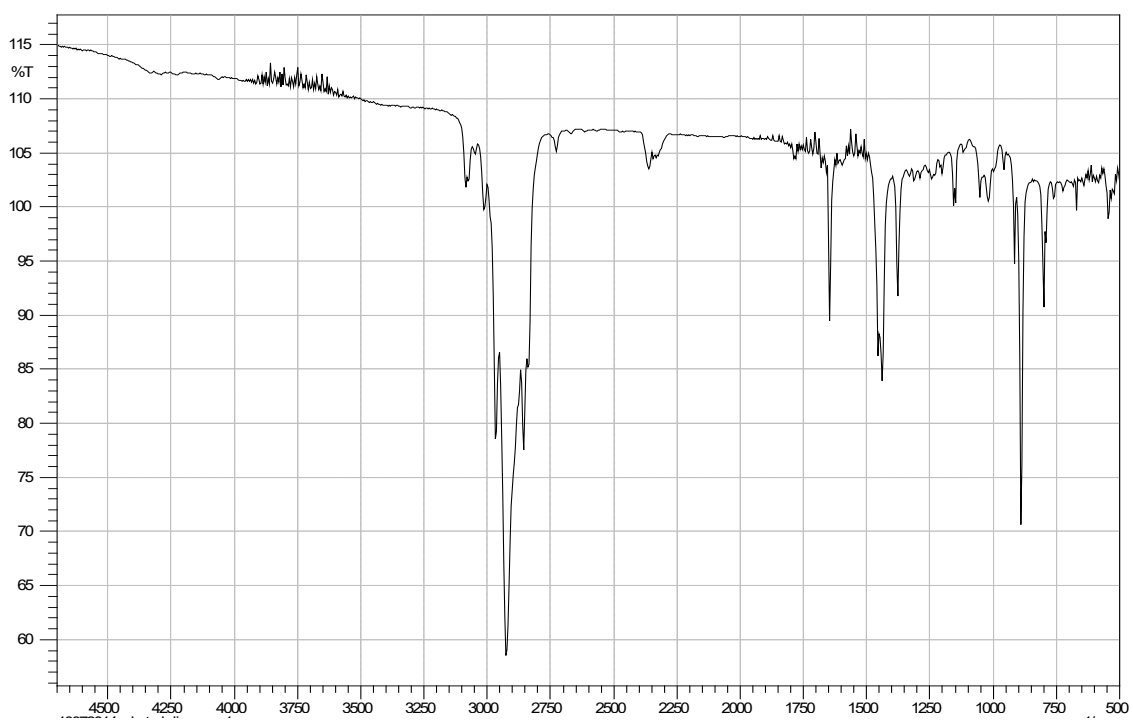

(a)

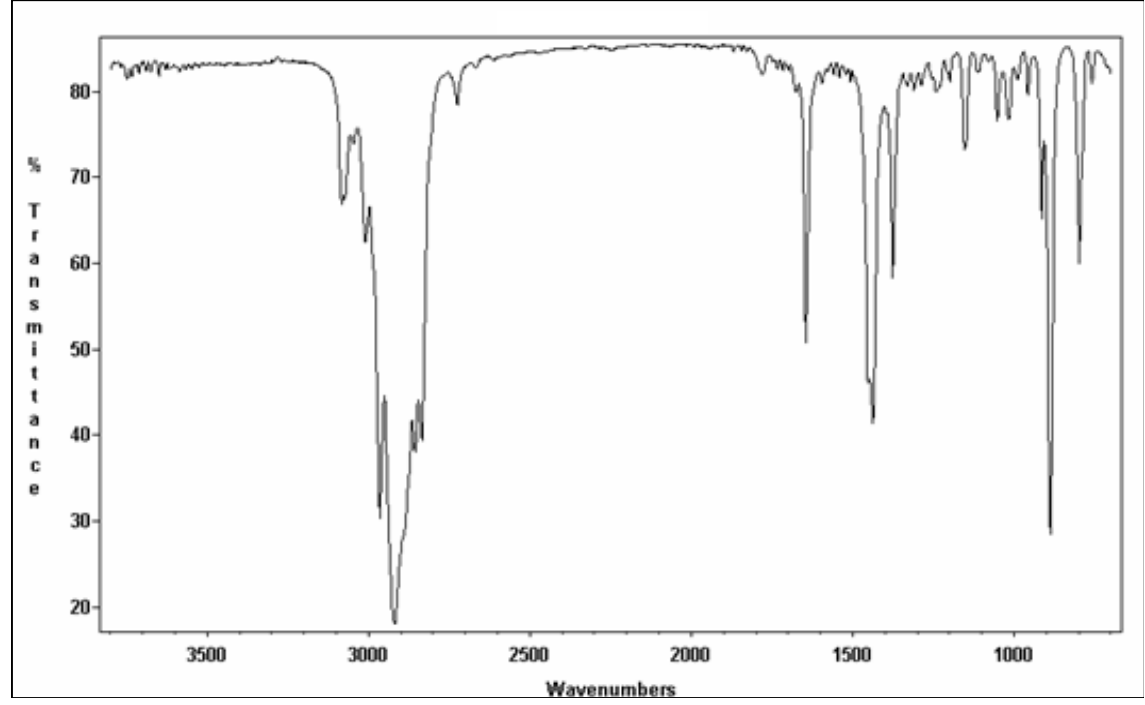

(b)

Gambar 1 Gambar Spektrum Inframerah Limonene, (a) Minyak Atsiri Kulit Jeruk Sunkist (b) Spektrum Limonene Murni ${ }^{10}$ 
Tabel 1 Penentuan Kadar Efektif Minyak Atsiri untuk Meluruhkan Sterofoam

\begin{tabular}{|c|c|c|c|c|c|}
\hline \multirow{2}{*}{ Formula } & \multirow{2}{*}{$\begin{array}{c}\text { Kadar Minyak Atsiri (\%v/v) } \\
\text { (MA:E:A) }\end{array}$} & \multicolumn{4}{|c|}{ Waktu hancur (detik) } \\
\hline & & I & II & III & IV \\
\hline A. & $100 \mathrm{MA}$ & 10,450 & 19,804 & 46,842 & 153,670 \\
\hline B. & $\begin{array}{l}50 \mathrm{MA}: 50 \mathrm{E} \\
\quad(1: 1: 0)\end{array}$ & 8,845 & 19,183 & 43,681 & 161,982 \\
\hline C. & $\begin{array}{c}50 \mathrm{MA}: 25 \mathrm{E}: 25 \mathrm{~A} \\
(2: 1: 1)\end{array}$ & 6,707 & 17,957 & 40,961 & 165,381 \\
\hline D. & $\begin{array}{c}25 \mathrm{MA}: 25 \mathrm{E}: 50 \mathrm{~A} \\
(1: 1: 2)\end{array}$ & 6,925 & 17,441 & 45,123 & 182,967 \\
\hline E. & $\begin{array}{l}25 \mathrm{MA}: 75 \mathrm{~A} \\
(1: 0: 3)\end{array}$ & 8,602 & 26,221 & 52,819 & $\begin{array}{c}195,071 \\
\text { (tidak seluruhnya } \\
\text { hancur) }\end{array}$ \\
\hline F. & $\begin{array}{c}25 \mathrm{MA}: 50 \mathrm{E}: 25 \mathrm{~A} \\
(1: 2: 1)\end{array}$ & 14,051 & 14,872 & 29,100 & 159 \\
\hline G. & $\begin{array}{c}10 \mathrm{MA}: 30 \mathrm{E}: 60 \mathrm{~A} \\
(1: 3: 6)\end{array}$ & 30,372 & 38,271 & 67,352 & $\begin{array}{c}261 \\
\text { (tidak seluruhnya } \\
\text { hancur) }\end{array}$ \\
\hline
\end{tabular}

Keterangan: MA: Minyak Atsiri Kulit Jeruk Sunkist ; E : Etanol; A : Air, I : Sterofoam papan pengumuman; II : Sterofoam kemasan elektronik; III : Sterofoam wadah makanan; IV : Sterofoam mie instan seduh.

sunkist segar. Minyak atsiri diambil dengan cara distilasi. Dari 300 gram kulit jeruk diperoleh minyak atsiri rata-rata sebanyak $5 \mathrm{~mL}(1,67 \%(\mathrm{v} / \mathrm{b}))$.

Salah satu kandungan dalam minyak atsiri yang didapatkan adalah limonene. Limonene merupakan senyawa yang bersifat non polar. ${ }^{7}$

Komponen utama kandungan minyak atsiri kulit jeruk adalah D-limonene. ${ }^{8}$ Limonene merupakan cairan tidak berwarna yang termasuk ke dalam hidrokarbon siklik terpen. D-isomer inilah yang membuat limonene memiliki bau yang sangat kuat khas jeruk $^{9}$

Hasil pengujian terhadap sterofoam menunjukkan bahwa minyak atsiri ini dapat meluruhkan sterofoam.

Untuk membuktikan bahwa minyak atsiri yang didapatkan mengandung limonene, maka dilakukan analisis kualitatif dengan menggunakan spektrofotometer inframerah. Hasil analisis yang dilakukan terhadap minyak atsiri menunjukkan bahwa spektrum yang dihasilkan mirip dengan pustaka spektrum inframerah limonene yang ditujukkan pada Gambar 1.

Berdasarkan data pada Tabel 1 . diperoleh kadar yang efektif adalah formula D yaitu dengan kadar minyak atsiri kulit eruk sunkist 25\%; dengan perbandingan minyak atsiri : etanol : air, yaitu $1: 1: 2$. Pada Formula $\mathrm{F}$ yaitu dengan kadar minyak atsiri yang sama yaitu $25 \%$; dengan perbandingan

Tabel 2 Massa Sterofoam Maksimal yang Dapat Diluruhkan menggunakan 1 mL Minyak Atsiri Kulit Jeruk Sunkist 25\% dengan Perbandingan Minyak Atsiri : Etanol : Air (1:1:2)

\begin{tabular}{lc}
\hline Jenis Sterofoam & Massa (mg) \\
\hline Sterofoam wadah makanan & 160 \\
Sterofoam papan pengumuman & 200 \\
Sterofoam kemasan barang elektronik & 190 \\
Sterofoam mie seduh instan & 110 \\
\hline
\end{tabular}




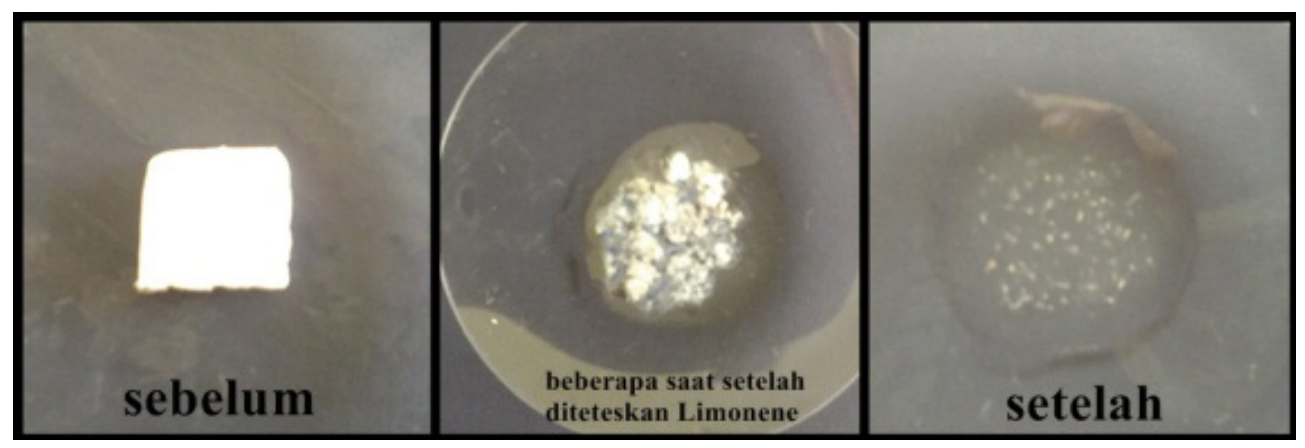

(a)

(b)

(c)

Gambar 2 Proses Peluruhan Sterofoam oleh Minyak Atsiri Kulit Jeruk Sunkist 25\%; dengan menggunakan Minyak Atsiri Limonene : Etanol : Air, (1:1:2) ; (a) Sterofoam sebelum diteteskan;(b)SterofoamsetelahBeberapasaatditeteskan;dan(c)Sterofoamsetelah diteteskan

minyak atsiri : etanol : air, yaitu 1:2:1 waktu yang digunakan untuk meluruhkan sterofoam lebih cepat dibandingkan formula $\mathrm{D}$, namun penggunaan air yang lebih banyak pada formula D lebih aman bagi lingkungan. Penggunaan etanol sendiri ditujukan untuk melarutkan minyak atsiri dan mempermudah distribusi partikel minyak atsiri dalam sterofoam.

Hasil pengamatan pada proses peluruhan menunjukkan bahwa massa sterofoam maksimal yang dapat diluruhkan oleh 1 $\mathrm{mL}$ formula $\mathrm{D}$ berbeda-beda tergantung pada jenis sterofoam yang digunakan. Sterofoam yang paling banyak diluruhkan adalah sterofoam papan pengumuman yaitu sebanyak $200 \mathrm{mg} / \mathrm{mL}$ minyak atsiri dengan formula D. Hasil penentuan kadar efektif minyak atsiri ditunjukkan pada Tabel 2.

\section{Simpulan}

Minyak atsiri kulit jeruk sunkist dapat digunakan sebagai peluruh sterofoam alami. Kadar minyak atsiri kulit jeruk sunkist yang efektif untuk meluruhkan sterofoam adalah $25 \%$; dengan perbandingan minyak atsiri : etanol : air, yaitu 1:1:2.

\section{Ucapan Terimakasih}

Penulis mengucapkan terima kasih kepada DIKTI yang telah memberi dukungan finansial terhadap penelitian ini, kepada Fakultas Farmasi Universitas Padjadjaran sebagai tempat melakukan penelitian dan kepada Ibu Driyanti Rahayu sebagai dosen pembimbing.

\section{Daftar Pustaka}

1. BPOM RI. 2008. Kemasan Polistirena foam (Sterofoam) (on line) [diakses tanggal 23 Januari 2016]. Tersedia online: http://perpustakaan.pom.go.id/ KoleksiLainnya/ Buletin\%20Info\%20 POM /0508.pdf.

2. Andersen CT. Keefektifan Sterofoam sebagai Material Kulit Bangunan Menginsulasi Panas. Prosiding Seminar Nasional AVoER ke-3; 26-27 Oktober 2011; Palembang, Indonesia. Indonesia: Universitas Sriwijaya; 2011.

3. Swandaru R. 2011. Pengaruh Penambahan Polivinil Alkohol dan Perbedaan Komposisi Ampok Jagung [diakses tanggal 17 Oktober 2013]. Tersedia online: http:// repository.ipb.ac.id/bitstream/ handle/123456789/48306/F11rsw_ Abstract.pdf.

4. Noguchi T, Miyashita M, Inagaki $\mathrm{Y}$, Watanabe H. A new recycling system for expanded polystyrene using a natural solvent. Part 1.A new recycling technique. Packag Technol Sci. 1998; 


\section{1:19-27.}

5. Sun J. D-Limonene: Safety and Clinical Applications. Alternative Medicine Review. 2007; $12: 3$.

6. Saleh, A. 2008. Extraction of The Essential Oil Limonene from Oranges [diakses 21 Oktober 2013]. Tersedia online: http:/www.reading.ac.uk/web/ FILES/chemistry/Limonene.pdf.

7. Burnharm, P.M. The industrial degreasing agent found in orange peel [diakses tanggal 20 Maret 2015]. Tersedia online at: http://www.chm. bris.ac.uk /motm/limonene/limoneneh. htm

8. Siburian R. Isolasi dan Identifikasi Komponen Utama Minyak Atsiri dari Kulit Buah Jeruk Manis (Citrus sinensis
L.) Asal Timor, Nusa Tenggara Timur. Jurnal Natur Indonesia. 2008; 11(1) : 8-13.

9. Fahlbusch, Karl-Georg; Hammerschmidt, Franz-Josef; Panten, Johannes; Pickenhagen, Wilhelm; Schatkowski, Dietmar; Bauer, Kurt; Garbe, Dorothea; Surburg, Horst. 2003. "Flavors and Fragrances"Ullmann's Encyclopedia of Industrial Chemistry. German: Wiley-VCH Verlag GmbH \& Co. KgaA.

10. Food and Agricultural Organization of The United Nations. 2004. Spesifications for Flavourings [diakses tanggal 5 Mei 2014]. Available online at: http://www.fao.org/ag/agn/jecfaflav/img/img/1326.gif. 